\title{
Producción cultural huachafa
}

\section{THE HUACHAFA'S CULTURAL PRODUCTION}

Cristina Dreifuss Serrano

Universidad de Lima

\section{RESUMEN}

La producción cultural contemporánea en nuestro medio se caracteriza por tener múltiples influencias, que dan como resultado productos finales diversos, eclécticos y, en muchos casos, percibidos como inadecuados. Los términos chicha o huachafo designan actitudes, bienes de consumo, productos culturales e, incluso, obras de arte, cuya imagen se remite a las características mestizas de nuestra sociedad. La combinación de tradiciones, caracteres locales, afanes modernizadores y la búsqueda de pertenencia a un entorno global son algunas de las fuerzas que confluyen en los productos mencionados. Al analizar lo huachafo desde un punto de vista tanto formal como social, se busca entender, a través de las manifestaciones cotidianas, culturales y artísticas, cuáles son las razones de fondo y los mecanismos detrás de estas creaciones. Se manifiesta un proceso de adecuación a nuevas condicionantes, así como la construcción de nuestras ciudades contemporáneas. Los productos huachafos son, por un lado, una clave de lectura de quiénes somos. Por otro, se vuelven parte de nuestra cotidianidad y en este diálogo puede darse la construcción de una nueva identidad: la identidad del peruano contemporáneo, que tiene de inga y tiene de mandinga.

PALABRAS CLAVE: producción cultural, estética, mestizaje, hibridación
ABSTRACT

Contemporary cultural production in our context is characterized by having multiple influences, which result in various final products, eclectic and, in many cases, perceived as inadequate. The terms chicha or huachafo design attitudes, consumer goods, cultural products and even works of art, whose image refer to the mixed characteristics of our society. The combination of traditions, local characters, modernization impulses and the search for belonging to a global environment are some of the forces making the aforementioned products possible. When analyzing huachafo from both a formal and a social point of view, we aim to understand, through everyday events, cultural and artistic manifestation, which are the reasons and mechanisms behind these creations. There is an adaptation process to new situations, and the construction of our contemporary cities. The huachafo products are, on one side, a key to read who we are. On the other hand, they become part of our everydayness and in this dialogue, there could provoke the construction of a new identity: that of the contemporary Peruvian who "tiene de inga y tiene de mandinga".

KEYWORDS: cultural production, aesthetics,

hybridization, mixed processes 


\section{INTRODUCCIÓN}

De entre los muchos peruanismos incorporados en nuestra habla cotidiana, huachafo es uno de los más antiguos y recurrentes. Para el VI Congreso Internacional de la Lengua Española, celebrado en Panamá en el año 2013, el diario El País publicó en el blog Papeles perdidos un atlas de las palabras representativas de cada país en el que se habla español. Pidieron a 20 escritores definir la palabra que, a su juicio, reflejaba mejor su país. Iván Thays, en representación del Perú, escogió el término huachafo.

Aunque se considera un sinónimo de cursi, su significado es más amplio y va de lo gramatical a lo sociológico. La huachafería es imitar o pretender ser lo que no es. Además, está relacionado con lo ostentoso, falta imperdonable en un país donde se sobrestima el perfil bajo. Su uso es tan subjetivo que resulta incluso huachafo el andar señalando las huachaferías de los demás. (Como se citó en Manrique Sabogal, 2013)

Aunque la decisión del término, frente a otros, pueda cuestionarse, es interesante cómo efectivamente se trata de una palabra de uso generalizado en el Perú, y, a pesar de esto, pasa lo que sucede con tantos peruanismos: su significado nos es claro, pero se nos dificulta dar una definición precisa. Con respecto a la propuesta por Thays, vale resaltar que se propone que huachafo no es solo una categoría estética, es decir, sobre la apariencia de las cosas, sino que también se trata de un término sociológico. Señalar a alguien como huachafo es emitir un juicio que trasciende lo formal. Se trata, además, de una actividad en la que los peruanos caemos con mucha facilidad. “[...] en el Perú, la huachafería constituye una sólida institución, casi un producto de exportación no tradicional que afecta a todas las actividades y a todos los niveles sociales" (Gildemeister, 2015).

El término chicha suele usarse como sinónimo, pero sin la carga peyorativa que parece ser inseparable de huachafo. Pareciera que a lo chicha le hemos cogido cariño, como una muestra de mestizaje urbano tolerado, incluso escogido, que ha ido impregnando música, moda, comida, publicidad y muchas otras esferas culturales. ¿Por qué, entonces, insistir en hablar de huachafo ligado a la producción cultural? Precisamente por el carácter social del término. Al huachafear, estamos combinando las apreciaciones que tenemos sobre lo formal como símbolo de lo social. Siendo los productos culturales reflejo de las sociedades, creo indispensable detenernos a analizar el término, sus manifestaciones y sus implicancias.

\section{POSIBLES ETIMOLOGÍAS}

Estuardo Núñez, citado por Federico Schwab (1940) y Martha Hildebrandt (1994), señala que el origen del peruanismo es el término colombiano guachafa. Se usa para hablar de fiestas bulliciosas y alegres, o también de desorden y alboroto. Cuenta Núñez que vino a Lima una familia de emigrantes colombianos con hijas jóvenes a quienes los 
padres querían buscar un "buen partido". Para tal efecto, organizaban fiestas en las que gastaban más de lo que sus posibilidades les permitían, con el fin de aparentar una posición económica acomodada y casar a sus hijas en consecuencia. Estas fiestas eran llamadas guachafas y, con el tiempo, las anfitrionas tomaron ese nombre.

Felipe Lucio Pezet (1993) sostiene que la palabra tiene un origen bastante distinto, con raíces en el idioma inglés. Durante la Revolución Industrial del siglo XVIII, en el Reino Unido, surge el barrio obrero de Whitechapel, habitado por trabajadores de fábricas textiles. Algunos llegan a tener una buena posición económica y se dedican a demostrarla con el uso de ropa y accesorios ostentosos. A estas personas se les llamó chaps from Whitechapel, y luego whitechaps. Cuando la administración de ferrocarriles peruanos en el siglo XIX se otorga a ciudadanos ingleses, una serie de inmigrantes llegan al Perú a trabajar en el rubro. Se dice que estos inmigrantes observan a los locales imitar las modas europeas y exagerar en el uso de accesorios, sin exactamente llegar a los logros de los modelos que buscan imitar. A estas personas los ciudadanos ingleses bautizan como whitechaps. Fonéticamente, el término pronto se convierte en huachafo.

Otro posible origen es la palabra quechua waqcha, que significa "pobre, huérfano o sin recursos". Durante la Colonia, estaba fuertemente cargada de connotaciones negativas (Knowlton, 2014). En español, la palabra se ha transformado en huacha, como un término general para cosas de baja calidad. Se sostiene que este es el paso intermedio entre el vocablo quechua y el huachafo actual.

El peruano Jorge Miota es señalado por Pinto Gamboa (1979) como quien introduce el término en la prensa escrita, en artículos presentados en periódicos y revistas limeños a inicios del siglo xx. La primera reflexión sobre el término se encuentra en un artículo publicado el 19 de abril de 1903 en El Comercio: "Tipos y costumbres: Las huachafas" (Pinto Gamboa, 1979, p. 141). Miota utiliza el término para describir "aquello que imita sin éxito, que exhibe sin rubor, que pretende ser lo que no es (ni puede ser: de allí el carácter violento y condenatorio del término)" (Hildebrandt, 2010).

\section{SIGNIFICADOS ADJUDICADOS}

Para muchos, el término huachafo no solo es un peruanismo: hay quienes insisten en que es un limeñismo, cerrando aún más su círculo de acción y dificultando su definición. "En primer lugar, la dificultad estriba en su relatividad. Todos somos susceptibles de huachafear y de ser huachafeados, es decir, de ser considerados huachafos por determinadas personas, y de poder, a nuestro turno, determinar que otras personas son huachafas" (Dreifuss Serrano, 2011b). A pesar de esto, es interesante notar cómo este término, con más de cien años de existencia, sigue teniendo vigencia, sin haber cambiado su significado de manera sustancial. Esto podría sugerir su pertinencia 
para describir dinámicas locales que se han mantenido a lo largo de las décadas. "La huachafería es al presente una institución, una gran familia nacional perfectamente caracterizada y cuyas relaciones, gustos y demás particularidades pueden catalogarse andando el tiempo para satisfacción de la historia patria" (Clemente Palma, como se citó en Pinto Gamboa, 1979, p. 147).

Algunos intentos por definir el término lo colocan como sinónimo de kitsch o cursi. Sin embargo, existe una diferencia sustancial, y es esta: huachafo, como se ha señalado, tanto como un término estético, es un término social. Esto es lo que tienen en común cada una de las posibles etimologías de la palabra. Schwab (1940) señala que kitsch o cursi designan "únicamente la oposición sustancial entre el espíritu y la forma de expresión en general, sin tener en cuenta el factor social. El hombre cursi [o el hombre kitsch] fracasa en una pretensión estética; el huachafo en una pretensión social o cultural" (p. 19).

Héctor Velarde (1966) coincide con esta postura, y añade que el problema del huachafo surge por una falta de relación entre la figura y el fondo de las cosas. Cuando la forma supera al fondo y se deja de dar una situación de equilibrio entre ambos factores, "la serenidad [que] se establece cuando el fondo y la forma coinciden" (p. 393), se presenta una situación huachafa.

Desde el punto de vista estético, también se puede establecer distinciones entre lo huachafo y lo kistch. 0 , para ser más precisa, lo huachafo es una variante local de lo kitsch, como puede serlo lo hortera en España o lo naco en México. Lo regional cobra importancia cuando, en la práctica, la imagen de las cosas huachafas no puede evitar reflejar aspectos formales que remiten al pasado de nuestra cultura. Si bien las palabras pueden funcionar como sinónimos, los objetos a los que es posible aplicar dicha descripción no lo son, y pueden constituir una producción artística o cultural regional. Sobre esto profundizaremos más adelante.

En 1964, Sebastián Salazar Bondy publica el ensayo Lima la horrible, que posteriormente se convertiría en libro. Dentro del provocador texto, menciona actitudes típicas de la huachafería de la ciudad:

Para ser lo que no se es se precisa de un disfraz. Demos una mirada alrededor y hallaremos decenas: la dependienta de una tienda que remeda los modelos de la damisela de las fiestas de sociedad, el burócrata que se reviste de forense gravedad verbal, el pequeño burgués que acomete su casita propia copiando en modesto los regustos arquitectónicos del palacio, el grafómano que redacta con hinchazón y vacuidad porque supone que así es una pluma académica. Estos son casos de disfracismo en pos de la categoría que no se tiene y que se presume superior, aunque de hecho no lo sea. Lo postizo es, en último término, huachafo, y según las previas categorías constituye antes lo huachafito, lo huachafoso y lo huachafiento. Importa, pues, la intención que dirige el mimetismo arribista. Juez excesivamente pegado a la letra para presumir, huachafo; madre que selecciona 
los futuros yernos por el apellido (sin que el propio tenga alcurnia), huachafa; hombre o mujer que en cualquier ocasión procuran exhibir cultura o cosmopolitismo, huachafos. (Salazar Bondy, 1964/2008, p. 108)

Dentro de la denuncia que se hace de las actitudes colonialistas que, a mitad del siglo $x x$, son aún evidentes para el autor, el rasgo en común que tienen las actitudes descritas es social. En todos los casos, se trata de intentos de movilidad social, de pretensiones por pertenecer a una clase superior, efectuados por "mujeres y hombres de medios económicos limitados, que esperaban mejorar su posición social a través de la manifestación pública de ostentación" (Parker, 1998, p. 32).

En un artículo bastante citado, Mario Vargas Llosa intenta precisar el significado de la palabra utilizando diversos ejemplos que representan actitudes y preferencias de diferentes grupos sociales peruanos. Habla de los políticos, de los oradores, de los religiosos y de la literatura. "Por su naturaleza, la huachafería está más cerca de ciertos quehaceres y actividades que de otros, pero, en realidad, no hay comportamiento u ocupación que la excluya esencialmente" (Vargas Llosa, 1983). Señala, además, que algunas de estas actitudes huachafas son esperadas, preferidas, o incluso indispensables para el éxito de determinadas empresas, como los discursos políticos. El autor, sin embargo, no profundiza en los aspectos sociales, y sus descripciones no pasan de ser un conjunto de anécdotas.

Se enfatiza, sin embargo, en el hecho de que todos somos susceptibles de ser huachafeados. Ningún grupo social está libre de ser huachafeado por otro, aunque esto es más frecuente en las clases bajas, a las cuales las clases medias o altas tildan de huachafas cuando las primeras presentan actitudes que las segundas consideran inadecuadas ${ }^{1}$. Sin embargo, son también huachafas las actitudes de la clase alta cuando busca ser pretenciosa más allá de sus posibilidades.

[Lo huachafo puede,] por momentos, designar una acción, y no necesariamente un estado social. Todo el mundo podía en un momento u otro ser tildado de huachafo. Más simple, más concreto: la más rancia encarnación del buen gusto occidental - español, francés o estadounidense- podría, en una fracción de segundo, convertirse en una huachafada. Bastaba para ello que se hiciera notar lo que era, por lo demás, evidente para todos, el mal gusto supremo que se escondía en estas formas de imitación y de impostura cultural. [...] no todo el mundo podía ser huachafo en todos los instantes ni con la misma intensidad, pero nadie estaba definitivamente al abrigo de la huachafada. Y del ridículo. (Martuccelli, 2015, p. 69)

1 En este sentido, se da una coincidencia con el "principio de inadecuación", señalado por Moles (1971, p. 71) como una de las características básicas de lo kitsch. 
Lo cierto es que lo huachafo aparece en el encuentro con el otro. Uno no es consciente de su propia huachafería hasta que esta viene señalada desde el exterior. Es, en ese sentido, "una categoría particular de descalificación cultural" (Martuccelli, 2015, p. 70). Así, el huachafo no está dentro del objeto o de la acción, sino en la percepción que otra persona tiene de la cosa.

\section{LO SOCIAL}

Dentro de una sociedad que nace de la rigidez de oponer a conquistadores y conquistados, las clases sociales se establecen sobre la base de una dualidad. Los matices emergen, casi desde el inicio, pero dicha rigidez inicial se mantendrá por mucho tiempo.

Con la movilidad social que se intensifica hacia fines del siglo $\mathrm{xx}$, se produce no solo el fenómeno de los grupos arribistas, sino también, como reacción inmediata, la censura a estos. Los grupos tradicionales, sobre todo quienes ostentaron el poder hasta ese momento, ven con suma desconfianza a quien busca ascender sin ser considerado merecedor.

Detrás del uso de la palabra huachafo hay algo mucho más profundo que la mera crítica del gusto. La obsesión con el escalador social -como se evidencia por la cantidad de artículos en la prensa dedicados a la discusión del huachafo- era un síntoma de una inhabilidad más grande de aceptar la movilidad social como parte de la vida cotidiana. Los peruanos, hemos visto, describían su orden social en términos de absolutos morales innatos: gente decente, gente de pueblo, y nunca los dos deberán encontrarse. Mientras que en un nivel seguramente se dieron cuenta de que las élites venían y se iban, en otro nivel su visión de la jerarquía social, construida lingüísticamente como una función de la esencia interna, no permitió un lugar conceptual para una clase media, ni un rol legítimo para el movimiento entre una casta y otra. (Parker, 1998, p. 33)

Entonces, la crítica estética y social esgrime un mecanismo de defensa que se basa en la anulación del otro a través de ridiculizarlo. Al tratarse de estándares ambiguos, conocidos y transmitidos por unos pocos, el personaje que aspira a un nuevo grupo evidencia su condición de origen. No encaja. Y esto es rápidamente señalado por los grupos establecidos, para quienes "[la] norma manda comportarse medida, respetuosamente, sin exageraciones exteriores, sin saltar las etapas de la promoción que, a falta de linaje, se ha hecho imperativo cumplir" (Salazar Bondy, 1964/2008, p. 107).

Salazar Bondy (1964/2008) coloca el fenómeno en un contexto en el que para el arribista se presentan dos caminos: "La subversión contra los opresores o la infiltración entre ellos" (p. 109). Mientras que la primera implica un enfrentamiento que requiere, además, de la conformación de un grupo cohesionado, la segunda es una maniobra que puede ser individual, y no siempre se hace evidente. 
La popularidad del término va en aumento a la par que la expansión urbana, desde la década de 1940 (Parker, 1998; Martuccelli, 2015). Este fenómeno trae a las ciudades, sobre todo a Lima, nuevos personajes y nuevos grupos. La expansión de las nuevas clases medias es el territorio perfecto para el cultivo de este aparentar que permitiría la infiltración en grupos más elevados. Y es ahí donde el huachafo es identificado por los grupos consolidados. "Si las apariencias y el engaño constituían las armas preferidas del arribista, la crítica a la huachafería era la mejor defensa del privilegiado" (Panfichi y Portocarrero, 1995, p. 171).

En estos nuevos grupos, las costumbres y poses adoptadas de otros generan una situación de "incongruencia entre la apariencia y la esencia" (Parker, 1998, p. 33), entre lo que se es en origen y lo que se quiere ser.

En otras palabras, la crítica del huachafo era en realidad una crítica a la inautenticidad. El que escala socialmente era acusado de ser culturalmente no refinado, pero su verdadero crimen era pretender ser alguien que supuestamente no era. El mismo concepto de inautenticidad es así predicado al aceptar la idea de que la posición social era de hecho un asunto de carácter moral innato y era permanentemente establecida al nacer. En breve, la crítica de la huachafería era, en el fondo, un intento de sostener esta ficción colectiva, a pesar de la abundante evidencia de que la movilidad social ocurría con regularidad, incluso en los rangos más altos de la élite. Por extensión, la caracterización de "la clase media" como típicamente huachafa (es decir, fingida e inauténtica) ilustraba una negativa a aceptar como legítima la existencia de un grupo inclasificable, no necesariamente respetable, pero tampoco enteramente plebeyo. En un mundo dividido entre gente decente y gente de pueblo, algo como "la clase media" no debería existir. (Parker, 1998, pp. 33-34)

Las clases altas, como señala Rivera Martínez (2003), se consideran poseedoras no solo de un patrimonio económico y político, sino también cultural y moral, que se resume en hablar de "buen gusto". Esta categoría, ambigua y variable, va a convertirse en un "parámetro autentificador y diferencial" (p. 38), que da al grupo dominante las credenciales que requiere para seguir manteniendo dicho dominio. Esta estrategia no es únicamente peruana, pero llama la atención, en nuestro caso, el carácter permanente que ha adoptado el término, a pesar de la siempre creciente movilidad social.

\section{LO HUACHAFO COMO PROCESO CREATIVO}

Las manifestaciones artísticas y culturales huachafas corresponden en su mayoría a un grupo creativo que podríamos llamar popular-urbano y son, por lo tanto, parte importante de la cultura popular contemporánea en el Perú. Muchas de las características formales de la cultura popular-urbana tienen que ver con la combinación de arte tradicional (herencia, muchas veces, de las zonas del interior de donde vienen sus creadores) y elementos artísticos y/o tecnológicos que sean entendidos como "modernos". Se trata 
de manifestaciones masivas, que buscan, generalmente, corresponder con las preferencias de grandes públicos (Dreifuss Serrano, 2010).

El objeto o proceso huachafo, en sí mismo, es un proceso creativo. La copia a las clases altas pasa por una serie de procesos en los que se combina aquello a lo que uno aspira (lo que se quiere ser) con los recursos personales producto del propio capital cultural (lo que se es). En dicho proceso, se involucra imaginación, creatividad, habilidad manual, tiempo y capitales, con la utilización de tres recursos (Dreifuss Serrano, 2011a):

\section{Proceso de conclusión}

El proceso de copia, frecuentemente, no considera las lógicas que están detrás de la creación del objeto original. Quien copia ve aspectos limitados de este, y se ve forzado a completarlo empleando sus propios recursos.

Al no conocer las lógicas, sistemas compositivos o razones de ser del objeto, los mecanismos propios del nuevo creador entran en funcionamiento y concluyen lo que se está queriendo hacer. En este sentido, es un proceso creativo. El producto final, sin embargo, tendrá características que, para los creadores o usuarios originales, hacen penosamente evidente su carácter de falsificación. Quien copió, por su parte, es completamente ignorante de esta situación.

\section{Enriquecimiento}

Dentro de las características propias del nuevo creador, el capital cultural de origen suele imponerse a las lógicas del objeto copiado. Para culturas en donde la decoración juega un rol predominante, la escasez de imágenes figurativas, la "limpieza" estilística de algunos objetos de diseño o los pocos recursos usados se perciben como un empobrecimiento del objeto en cuestión.

Entonces, como parte de la copia, el nuevo creador busca "hacerlo mejor", colocarle adornos, materiales que se ven más ricos, mayor intensidad en colores y formas.

Siempre me ha gustado el detalle, hacer una buena fachada, sugerirle al dueño. A veces, por la economía, el dueño me decía: "No, así no más hazlo", pero yo le decía: “Qué tal si hacemos una figurita aunque sea?". El dueño, encantado de la vida, decía: "Hay que hacerla", y se quedaba bien contento. (Chuquiruna, 2009, p. 166)

El nuevo creador percibe entonces que el objeto resultante es más rico, más vistoso, más sabroso.

\section{Abaratamiento}

Aunque suene contradictorio, este recurso también se pone en práctica de manera simultánea, y la razón es puramente pragmática. En la mayoría de los casos, el nuevo 
creador no tiene los recursos económicos para elaborar una copia fiel del original, por lo que utiliza materiales similares, de menor calidad, que tratan de aparentar los acabados del objeto original. Nuevamente, esto hará que la copia sea penosamente evidente para los creadores y usuarios originales.

Como en el camp, existe actualmente una moda de lo huachafo: las formas tradicionalmente relacionadas con las clases populares están siendo tomadas y estilizadas por los productores de arte "oficial", y son ahora consumidas, parcialmente, por aquellos grupos que originalmente las despreciaban.

Unos de los primeros ejemplos de este camp-huachafo se encuentra en la ropa, con la creación de las llamadas modas urbanas, que incorporan conocidos íconos de la cultura popular-urbana en prendas de vestir destinadas a segmentos socioeconómicos altos. Otros ejemplos se han dado en la publicidad y las artes gráficas; en estas últimas, en paralelo a las corrientes que han buscado un constante diálogo con la cultura popular (corrientes con presencia continua, pero muchas veces marginal), aparecen artistas de renombre que utilizan imágenes recurrentes de lo huachafo y las "academizan", para ser luego colocadas en un museo (Dreifuss Serrano, 2010).

\section{NOTAS FINALES}

Como última observación, podemos hablar de un nuevo tipo de huachafo. Este no es producto del proceso creativo descrito, sino que busca la copia fácil, la imitación efectista y barata, muchas veces con fines de entretener. Ejemplo de esto es el edificio del Ministerio de Educación (Lima, 2011), copia del edificio Palmas (México, 1975).

La generalización de esta copia barata hace que lo que antes se consideraba huachafo deje de ser censurable. Como señala César Hildebrandt (2010):

Hoy los huachafos han salido del armario y han tomado el poder. Nadie huye hoy de la huachafería. Al contrario: se la ha adoptado porque se ha impuesto y porque es rentable. La prensa "no huachafa", por ejemplo, parece condenada a la miseria. La TV "no huachafa" ha dejado, sencillamente, de existir.

En el primer caso, el fenómeno de copia parte de procesos afectivos, de apropiación y de genuino interés estético. El producto mediocre se debe a la ingenuidad. El otro tipo de copia es efectuada por quienes conocen o deberían conocer, y se debe a la pereza o a la poca inversión cultural. El producto final, en su mediocridad, es censurable. 


\section{REFERENCIAS}

Chuquiruna, O. (2009). Diseñando la ciudad. En S. Bedoya (Ed.), Coloquio Lo Cholo en el Perú. Migraciones y mixtura (pp. 165-172). Lima: Biblioteca Nacional del Perú.

Dreifuss Serrano, C. (19 de abril del 2010). 10 ideas sobre lo huachafo (desarrolladas) [mensaje en un blog]. Recuperado de http://arquitecturahuachafa.blogspot. pe/2010/04/10-ideas-sobre-lo-huachafo_14.html

Dreifuss Serrano, C. (2011a). Huaycán. A case study in spontaneous architecture. En Informality: Re-viewing Latin American cities. Cambridge, UK: CRASSH (The Centre for Research in the Arts, Social Sciences and Humanities).

Dreifuss Serrano, C. (2011b). L'estetica (del huachafo) nell'architettura contemporanea a Lima (tesis doctoral). Università degli Studi di Roma La Sapienza, Italia.

Gildemeister, A. (13 de abril del 2015). ¿Cuándo se huachafió el Perú? Lucidez. Recuperado de http://www.lucidez.pe/nacional/cuando-se-huachafio-el-peru/

Hildebrandt, C. (14 de febrero del 2010). Miota y la huachafería [mensaje en un blog]. Recuperado de http://bloghildebrandt.blogspot.pe/2010/02/miota-y-la-huacha feria.html

Hildebrandt, M. (1994). Peruanismos. Lima: Biblioteca Nacional del Perú.

Knowlton, D. (13 de agosto del 2014). Huachafo, a key word in Peru. Cusco Eats. Recuperado de http://cuzcoeats.com/huachafo-a-key-word-in-peru/

Lucio Pezet, F. (1993). Del origen de las palabras y las frases: breviario de etimología histórica de palabras, locuciones y frases. Lima: Talleres Gráficos.

Manrique Sabogal, W. (23 de octubre del 2013). Atlas sonoro /6: Elige las palabras de Perú, Paraguay y República Dominicana [mensaje en un blog]. Recuperado de http:// blogs.elpais.com/papeles-perdidos/2013/10/atlas-sonoro-6-elige-las-pala bras-de-peru-paraguay-y-republica-dominicana.html Martuccelli, D. (2015). Lima y sus arenas. Poderes sociales y jerarquías culturales. Lima: Cauces Editores.

Moles, A. (1971). Psychologie du Kitsch. L'art du bonheur. París: Maison Mame.

Panfichi, A., y Portocarrero, F. (1995). Mundos interiores: Lima 1850-1950. Lima: Universidad del Pacífico, Centro de Investigación.

Parker, D. S. (1998). Idea of the middle class: white-collar workers and Peruvian society, 1900-1950. Pensilvania: The Pennsylvania State University Press.

Pinto Gamboa, W. (1979). Envés y reflexión de lo huachafo (Jorge Miota: vida y obra). Lima: Imprenta de la Universidad Mayor de San Marcos. 
Rivera Martínez, E. (2003). Estampas de ocio, buen humor y reflexión. Lima: Universidad Nacional Mayor de San Marcos, Fondo Editorial.

Salazar Bondy, S. (2008). Lima la horrible. Concepción: Editorial Universidad de Concepción. (Trabajo original publicado en 1964).

Schwab, F. (1940). Lo huachafo como fenómeno social. Revista 3, 4, 16-22.

Vargas Llosa, M. (28 de agosto de 1983). ¿Un champancito, hermanito? El Comercio.

Velarde, H. (1966). Contribución al estudio de la huachafería en el arte. En Obras completas (II) (pp. 393-396). Lima: Francisco Moncloa Editores. 